\title{
BMJ Open Quality of life of adolescents with menstrual problems in Klang Valley, Malaysia: a school population-based cross-sectional study
}

\author{
Uma Mariappen, ${ }^{1}$ Kah Teik Chew (D) , ${ }^{2}$ Ani Amelia Zainuddin, ${ }^{2}$ \\ Zaleha Abdullah Mahdy (D) ,2 Nur Azurah Abdul Ghani, ${ }^{2}$ Sonia Grover ${ }^{3}$
}

To cite: Mariappen U, Chew KT, Zainuddin AA, et al. Quality of life of adolescents with menstrual problems in Klang Valley, Malaysia: a school population-based crosssectional study. BMJ Open 2022;12:e51896. doi:10.1136/ bmjopen-2021-051896

- Prepublication history for this paper is available online. To view these files, please visit the journal online (http://dx.doi org/10.1136/bmjopen-2021051896).

Received 31 March 2021 Accepted 08 December 2021

Check for updates

(c) Author(s) (or their employer(s)) 2022. Re-use permitted under CC BY-NC. No commercial re-use. See rights and permissions. Published by BMJ.

${ }^{1}$ Department of Obstetrics \& Gynaecology, Universiti Kebangsaan Malaysia, Bangi, Malaysia

${ }^{2}$ Department of Obstetrics \& Gynaecology, Universiti Kebangsaan Malaysia Medical Centre, Cheras, Malaysia

${ }^{3}$ Department of Paediatric and Adolescent Gynaecology, Royal Children's Hospital, Melbourne, Victoria, Australia

Correspondence to

Dr Kah Teik Chew;

drchewkt@gmail.com

\section{ABSTRACT}

Objective To describe the prevalence of menstrual problems (heavy menses bleeding, dysmenorrhoea and oligomenorrhoea) and its impact towards quality of life among adolescents in Klang Valley, Malaysia.

Design Cross-sectional study.

Setting Adolescent girls at secondary schools in the Klang Valley, Malaysia.

Population 729 adolescents aged between 13 and 18 years.

Method A questionnaire survey using Menorrhagia Questionnaire and Paediatric Quality of Life-Teen Report Ages 13-18 (PedsQL).

Main outcome measures Self reports of menstrual bleeding patterns, morbidities and effect on quality of life. Results The prevalence of menstrual problems among adolescents was $63.9 \%$ in the Klang Valley. Adolescents with menstrual problems had significant lower mean total score of PedsQL $(70.23 \pm 13.53$ vs $76.36 \pm 14.93$, $\mathrm{p}=0.001)$, physical health summary score $(74.10 \pm 16.83$ vs $79.00 \pm 15.86, p<0.001)$ and psychosocial health summary score $(68.05 \pm 14.27$ vs $73.21 \pm 13.09, p=0.001)$ compared with those without menstrual problem. Adolescents experiencing heavy menses bleeding had the lowest physical and emotional function. Those with oligomenorrhoea had the lowest social function, whereas those with dysmenorrhoea had the lowest school function. Cigarette smoking, alcohol and medical illness had lower health-related quality of life, whereas taking oral contraceptive pills for menstrual problems was associated with higher scores in these adolescents.

Conclusion Menstrual problems among adolescents have a significant impact on their quality of life. It is probably wise to screen them at the school level, to identify those with low functional scores and to refer them for proper management at a tertiary adolescent gynaecology centre.

\section{INTRODUCTION}

Menstrual problems among adolescent females are common. It is estimated that $75 \%$ of them would experience some disorders associated with menstruation. ${ }^{1}$ The most common menstrual problems among adolescents worldwide are heavy menses bleeding
Strengths and limitations of this study

- This was the largest school population-based crosssectional study been conducted to evaluate the quality of life of adolescents with menstrual problems in Malaysia.

- This was the first study conducted in Malaysia among adolescents using Paediatric Quality of LifeTeen Report Ages 13-18 (PedsQL).

- This study used PedsQL, a better tool to reflect impact of menses problems to adolescents, particularly in social and school function.

- Confounding factors were further analysed to give a clearer picture regarding the impact on healthrelated quality of life among adolescents with menstrual problems.

- The study focused only at urban area, and the findings might not be applicable to the whole adolescents' population in Malaysia.

(HMB), oligomenorrhoea, dysmenorrhoea, amenorrhoea and premenstrual syndrome.

HMB is defined as excessive blood loss more than $80 \mathrm{~mL}$ per menses and accounts for a substantial proportion of healthcare resources among females of reproductive age. Although approximately $30 \%$ of adult females reported problem of HMB, its prevalence among adolescents varied worldwide, ranged from $10 \%$ to $30 \% .^{23} \mathrm{HMB}$ requires medical intervention as increased blood loss may be indicative of a serious disease that requires urgent intervention. However, even in the absence of a medical problem, help is warranted because of the disability that a woman experiences as a consequence of menstrual periods.

Dysmenorrhoea affects $60 \%-93 \%$ of adolescents and is characterised by recurrent cramping abdominal pain associated with nausea. ${ }^{45}$ More than half of these girls missed school as a consequence of this problems. ${ }^{5}$ Dysmenorrhoea and HMB were associated 
with poor academic performance and limitation in outdoor activities whereas amenorrhoea was associated with low self-esteem. ${ }^{6-10}$

Although effective therapies for menstrual disorders exist, most of adolescents do not recognise their menses problems as a treatable medical conditions and do not always discuss their problems with healthcare providers. ${ }^{11}$ Only about $2 \%$ of teenagers in USA received information regarding menstruation from their healthcare providers. ${ }^{12}$ In Malaysia, only $11.1 \%$ of adolescents sought medical consultation for their menstrual disorders. ${ }^{7}$

In recent times, the concept of 'quality of life' has been used to quantify the effect of disease to patients. ${ }^{13}$ Menstruation-related problems contribute to school absenteeism and significantly add to the problems faced by adolescents and their families during this complicated phase of development. The age of menarche continues to decrease in this population, and hence increase the possibility that menstrual-associated morbidities may have a greater negative impact in their lives. ${ }^{14}$ Hence, it is important to study the effects of menstrual disorders among adolescents.

To date, most published literatures looked into the prevalence of menstrual disorders among adolescents. However, only a few studies have investigated the quality of life of adolescents with menstrual disorders. ${ }^{15-17}$ These studies used the Medical Outcome Survey 36-item short form health survey and Child Health QuestionnaireChild Self Report Form to assess the quality of life among young females with specific menstrual problems. Although they demonstrated the negative impact on their lives, neither of these tools included the impact on school performance and activities, which is an integral part of an adolescent's life.

Therefore, this study was designed to determine the prevalence of menstrual disorders and to evaluate the quality of life scores among adolescents with menstrual problems at Klang Valley in Malaysia. Besides that, the study also aimed to identify predictors of low quality of life scores in these adolescents. This may help clinicians to identify adolescents at risk of poor quality of life and improve the identified modifiable predictors or factors.

\section{METHODS}

\section{Participants and recruitment}

The study was conducted over a period of 1 year, involving 1050 adolescents aged 13-18years old from 20 selected secondary schools in Klang Valley, Malaysia. The 20 schools were randomly selected from 207 schools by computer generated randomisation. Sample size was calculated by using Kish formula with prevalence of menstrual disorder among adolescents of $75 \%$. The total sample required was 750 adolescents. The study was conducted in the selected schools with the permission of the school principal and class teachers. The adolescents were selected by simple randomisation method. They were given the information sheet and parental consent form 1 week before the questionnaire was provided. Only those who returned the parental consent form were recruited. They were given $30 \mathrm{~min}$ to complete the self-administered questionnaire. Those with intellectual disability, inadequate reading skills or significant psychiatric problem, and those who were known to be pregnant or had previously been pregnant were excluded from this study.

\section{Questionnaire}

For the purpose of this study, the original Menorrhagia Questionnaire (MQ) in English was translated into three languages (Bahasa Malaysian, Mandarin and Tamil) by the Malaysian Translators Association, a certified professional body in Malaysia for the purpose of translation or interpretation of any document into multiple languages. The Paediatric Quality of Life-Teen Report Ages 13-18 (PedsQL) has a validated questionnaire in Malay, Mandarin and Tamil. It was used with the permission of the Mapi Research Trust, Lyon, France.

The MQ is a 13-items questionnaire designed by Ruta et al. ${ }^{18}$ However, only the first seven questions of this tool were used to classify the type of menstrual problem in this study. The PedsQL is a brief 23-item multidimensional instrument designed by Varni et al for measuring paediatric health-related quality of life (HRQL) ${ }^{19}$ It consists of four parts: (1) physical functioning with eight items, (2) emotional function with five items, (3) social function and (4) school function, both with five items, respectively. The validity of PedsQL is well established. ${ }^{20}$ The instructions asked how much a problem each item posed over the past month. The response scale used a 5-point Likert-type format ranging from 0 to 4 , in which 0 indicated never a problem while 4 indicated almost always a problem. The raw score for each item was reverse-scored $(0=100$, $1=75,2=50,3=25$ and $4=0)$ and transformed to a scale of $0-100$, with higher scores indicating better HRQL. ${ }^{20}$ The total score was presented as mean score, computed as the sum of items divided by the number of items assessed by all scales. The Physical Health Summary score consisted of 8 items as similar as physical function part, while the Psychosocial Health Summary score included 15 items from emotional function, social and school function.

Data on the demographic information were incorporated into the questionnaire. The data collection process was piloted with 50 adolescents at a secondary school selected at random. This was undertaken to confirm the length of time required to complete the questionnaire and to refine the contents and process based on feedback from the participants. From the pilot study, the Cronbach alpha was 0.812 with no negative feedback received. The questionnaire took about $20 \mathrm{~min}$ to complete with no difficulties. Therefore, the study was commenced 1 week after the pilot test.

\section{Data analysis}

All data were collected in an electronic database and analysed using SPSS V.23.0. Mean was used for normally distributed continuous variables and analysis of variance 
Table 1 Demographic data of the study population $(\mathrm{N}=729)$

\begin{tabular}{lrr}
\hline Variables & $\mathbf{n}$ & $\%$ \\
\hline Race & & \\
\hline Malay & 453 & 62.1 \\
\hline Chinese & 210 & 28.8 \\
\hline Indian & 57 & 7.8 \\
\hline Others & 9 & 1.2 \\
\hline Religion & & \\
\hline Buddhist & 187 & 25.7 \\
\hline Christian & 36 & 4.9 \\
\hline Hindu & 48 & 6.6 \\
\hline Islam & 457 & 62.7 \\
\hline Sikh & 1 & 0.1 \\
\hline Siblings & & \\
\hline 0 & 25 & 3.4 \\
\hline 1-3 & 326 & 44.7 \\
\hline$>3$ & 378 & 51.9 \\
\hline BMl & & \\
\hline$<20$ underweight & 39 & 5.3 \\
\hline 20-24.9 normal & 431 & 59.1 \\
\hline 25-29.9 overweight & 19 & 30.9 \\
\hline Job obese & 225 & 7.4 \\
\hline Part-time & 54 & \\
\hline Not working & & \\
\hline
\end{tabular}

All data are presented in frequency (\%).

BMI, body mass index.

test was used to compare mean score for PedsQL. SD, a summary measure of the differences of each observation from the mean, was also calculated. Logistic regression analysis was used to determine the predictor factors for HRQL.

\section{Patient and public involvement}

Patients or the public were not involved in the design, or conduct, or reporting, or dissemination plans of this study.

\section{RESULTS}

A total of 1050 adolescents were approached with all parent consented to participate in this study. Only 729 adolescents $(69.4 \%)$ completed and returned the questionnaire for analysis. A total of 89 adolescents $(8.5 \%)$ did not return the questionnaire and $232(22.1 \%)$ returned incomplete questionnaire.

The demographic characteristics of sample population are presented in table 1 . The majority of the sample population were Malays $(62.1 \%)$, followed by Chinese $(28.8 \%)$, Indian $(7.8 \%)$ and others $(1.2 \%)$. Surprisingly, more than half $(59 \%)$ of the respondents were underweight, with only $31 \%$ of them had a normal body mass
Table 2 Social characteristics of the study population $(\mathrm{N}=729)$

\begin{tabular}{|c|c|c|}
\hline Variables & $\mathbf{n}$ & $\%$ \\
\hline \multicolumn{3}{|l|}{ Cigarette } \\
\hline Never & 697 & 95.6 \\
\hline Once or twice & 11 & 1.5 \\
\hline Once in a while but not regularly & 17 & 2.3 \\
\hline Regularly in the past & 4 & 0.5 \\
\hline \multicolumn{3}{|l|}{ Cigarette in 30 days } \\
\hline Not at all & 719 & 98.6 \\
\hline Less than one cigarette per day & 5 & 0.7 \\
\hline $1-5$ cigarettes per day & 3 & 0.4 \\
\hline $6-9$ cigarettes per day & 1 & 0.1 \\
\hline 20 or more cigarettes per day & 1 & 0.1 \\
\hline \multicolumn{3}{|l|}{ Alcohol } \\
\hline Never & 678 & 93.0 \\
\hline Once & 20 & 2.7 \\
\hline Twice & 11 & 1.5 \\
\hline $3-5$ times & 9 & 1.2 \\
\hline $6-9$ times & 1 & 0.1 \\
\hline 10 or more times & 10 & 1.4 \\
\hline \multicolumn{3}{|l|}{ Involved in sexual relationship } \\
\hline Yes & 21 & 2.9 \\
\hline No & 708 & 97.1 \\
\hline \multicolumn{3}{|l|}{ Contraception } \\
\hline Yes & 5 & 0.7 \\
\hline No & 724 & 99.3 \\
\hline \multicolumn{3}{|c|}{ Taken oral contraception pills for menstrual problems } \\
\hline Yes & 28 & 3.8 \\
\hline No & 701 & 96.2 \\
\hline
\end{tabular}

All data are presented in frequency (\%).

index (BMI). About $5.3 \%$ of the sample population were working part-time to support the family, after school and during the weekends.

Table 2 shows the social characteristics of the study population. In the sample population, $95.6 \%$ did not smoke. The majority of them $(93.0 \%)$ did not take alcohol in the past 2 weeks. Twenty-one adolescents (3\%) from the sample population were involved in a sexual relationship. Only $5(0.7 \%)$ of the sexually active adolescents practised contraception.

A large proportion of adolescents had learnt about menstruation from their mothers $(78.3 \%)$ and from school $(49.3 \%)$. About $25 \%-30 \%$ of them had gained knowledge from friends and books or magazines. The use of the internet among adolescents as the source of information was low at $3.4 \%$, and a very small percentage $(1.7 \%)$ learnt about menstruation from their fathers. The majority of the sample population $(94 \%)$ had no medical problems. The most common medical problem seen 
Table 3 Sociodemographic of adolescents with menstrual problems

\begin{tabular}{|c|c|c|c|c|}
\hline & HMB (n=205) & Dysmenorrhoea $(n=225)$ & $\begin{array}{l}\text { Amenorrhoea/ } \\
\text { oligomenorrhoea }(n=36)\end{array}$ & $P$ value \\
\hline Age (years) mean $\pm S D$ & $15.71 \pm 1.41$ & $15.81 \pm 1.69$ & $15.42 \pm 1.40$ & 0.608 \\
\hline \multicolumn{5}{|l|}{ Ethnicity } \\
\hline Malay & $140(46.8 \%)$ & $140(46.8 \%)$ & $19(6.4 \%)$ & 0.047 \\
\hline Chinese & $48(41.1 \%)$ & $53(45.2 \%)$ & 16 (13.7\%) & \\
\hline Indian & $16(35.6 \%)$ & $28(62.2 \%)$ & $1(2.2 \%)$ & \\
\hline Others & $1(20.0 \%)$ & $4(80.0 \%)$ & $0(0.0 \%)$ & \\
\hline $\mathrm{BMI}>30$ & $5(33.6 \%)$ & $9(60.0 \%)$ & $2(13.3 \%)$ & 0.023 \\
\hline \multicolumn{5}{|l|}{ Job } \\
\hline Part-time & $17(46.0 \%)$ & $15(40.5 \%)$ & $5(13.5 \%)$ & 0.423 \\
\hline Not working & $188(43.8 \%)$ & $210(49.0 \%)$ & $31(7.2 \%)$ & \\
\hline \multicolumn{5}{|l|}{ Alcohol } \\
\hline Yes & $12(41.4 \%)$ & $15(51.7 \%)$ & $2(6.9 \%)$ & 0.980 \\
\hline No & $193(44.1 \%)$ & $210(48.1 \%)$ & $34(7.8 \%)$ & \\
\hline \multicolumn{5}{|l|}{ Smoking } \\
\hline Yes & $12(48.0 \%)$ & $11(44.0 \%)$ & $2(8.0 \%)$ & 0.719 \\
\hline No & $193(43.8 \%)$ & $214(48.5 \%)$ & $34(7.7 \%)$ & \\
\hline \multicolumn{5}{|l|}{ Sexual } \\
\hline Yes & $6(42.9 \%)$ & $8(57.1 \%)$ & $0(0.0 \%)$ & 0.697 \\
\hline No & $199(44.0 \%)$ & $217(48.0 \%)$ & $36(8.0 \%)$ & \\
\hline \multicolumn{5}{|c|}{ Taken OCPs for menstrual problems $\mathrm{n}(\%)$} \\
\hline Yes & $15(53.7 \%)$ & $11(39.2 \%)$ & $2(7.1 \%)$ & 0.388 \\
\hline No & $191(43.6 \%)$ & $214(48.7 \%)$ & $34(7.7 \%)$ & \\
\hline \multicolumn{5}{|l|}{ Medical problem n (\%) } \\
\hline Yes & 15 (45.4\%) & 16 (48.5\%) & 2 (6.1\%) & 0.946 \\
\hline No & 190 (43.8\%) & 209 (48.3\%) & 34 (7.9\%) & \\
\hline
\end{tabular}

Analysis of variance test.

All data are presented in frequency (\%).

BMI, body mass index.

was asthma (2.7\%), followed by gastritis and anaemia (1.2\% each). Others include heart disease, thalassaemia, anxiety disorder, recurrent urinary tract infection and orthopaedic-related problems.

Out of the total 729 adolescents who had menses, only $28(4 \%)$ had taken oral contraceptive pills (OCPs) for menstrual problems. The mean age for menarche in the study population was $12.14 \pm 1.11$ years old. The prevalence of menstrual problems was $63.9 \%$ (466) among the studied adolescents. The majority of them, 225 (30.9\%) experienced dysmenorrhoea, followed by 205 (28.1\%) had HMB, $33(4.5 \%)$ had oligomenorrhoea and $3(0.4 \%)$ with amenorrhoea.

The prevalence of adolescents with menstrual problems was $63.9 \%$ among the study population. The most common menstrual problem was dysmenorrhoea (30.9\%), followed by HMB (28.1\%) and amenorrhoea/oligomenorrhoea $(4.9 \%)$. The sociodemographic characteristics of the adolescents with different menstrual problems are presented in table 3. There was a significant predisposition of dysmenorrhoea as the most common menstrual disorder across all ethnicities. Obesity (BMI $>30)$ was also predominant in the dysmenorrhoea group. Among the sexually active group, $14(66.7 \%)$ had menstrual problems and $7(33.3 \%)$ had no menstrual problems.

Overall, adolescents with menstrual problems had significant lower mean total score of PedsQL $(70.23 \pm 13.53$ vs $76.36 \pm 14.93, \mathrm{p}=0.001$ ), physical health summary score $(74.10 \pm 16.83$ vs $79.00 \pm 15.86, \mathrm{p}<0.001)$ and psychosocial health summary score $(68.05 \pm 14.27$ vs $73.21 \pm 13.09$, $\mathrm{p}=0.001$ ) compared with those without menstrual problem. There was a significant difference in all four domains of the PedsQL between adolescents with normal menses and those with menstrual problems. Adolescents with menstrual problem had lower scores compared with the normal population (table 4). Those with HMB have the lowest total score, and physical health functioning and the lowest psychosocial scores (table 5). HMB alone 
Table 4 Comparison of Paediatric Quality of Life-Teen Report Ages 13-18 scores

\begin{tabular}{lllr}
\hline & Normal $(\mathbf{n}=\mathbf{2 6 3})$ & Menstrual problems $(\mathbf{n}=\mathbf{4 6 6 )}$ & P value \\
\hline Physical & $79.00 \pm 15.86$ & $74.10 \pm 16.83$ & $<0.001$ \\
Emotional & $65.98 \pm 20.79$ & $59.08 \pm 20.61$ & $<0.001$ \\
Social & $82.29 \pm 16.42$ & $78.03 \pm 17.70$ & 0.001 \\
School & $74.97 \pm 15.78$ & $70.94 \pm 17.44$ & 0.002 \\
Total score & $76.36 \pm 14.93$ & $70.23 \pm 13.53$ & 0.001 \\
\hline
\end{tabular}

Independent t-test.

All data are presented in mean \pm SD.

contributed to a lower physical score compared with dysmenorrhoea and amenorrhoea/oligomenorrhoea. Amenorrhoea/oligomenorrhoea had the lowest social function and dysmenorrhoea had the lowest school function. However, these differences were not statistically significant (table 5).

Table 6 summarises the influence of demographic, clinical status and social factors on HRQL. In the linear regression, cigarette smoking, alcohol and medical illness had negative relationships with HRQL. This indicates that the more the adolescents smoked, drank alcohol and had medical problems, the lower the functional scores. Similarly, there was positive relationship with taking oral contraceptive pills for menstrual problems.

\section{DISCUSSION}

The study revealed that the prevalence of menstrual disorders in the Klang Valley was $63.9 \%$. The most common menstrual problem seen in the study population was dysmenorrhoea $(30.9 \%)$, followed by HMB (28.1\%), oligomenorrhoea $(4.5 \%)$ and amenorrhoea $(0.4 \%)$. This was similar to other studies performed in the past. ${ }^{711221}$ The mean age of adolescents at menarche in this study was $12.14 \pm 1.11$, which was also similar to most the previous studies. ${ }^{1122}$

HMB was found in $28.1 \%$ of adolescents. This was much higher compared with only $18 \%$ of the sample population suffering from HMB in previous literature. ${ }^{7}$ This could be attributed to the sedentary life-style, increasing obesity and stress level among adolescents. ${ }^{23-26}$ HMB often occurred after menarche due to anovulatory cycles with an immature hypothalamic-pituitary-ovarian axis. ${ }^{27}$ HMB could be an emotional stress as evidenced by lowest mean emotional function score among the studied adolescents. This finding was similar compared with other studies. ${ }^{162}$ In the present study, adolescents often felt depressed, helpless and worried with their HMB. These emotional feelings had direct negative impact to their school and social performance. Pawar et al found that more than half of adolescents were reported missing from school due to HMB. ${ }^{29}$ Unfortunately, these debilitating psychosocial implications are often overlooked and neglected as clinicians always focus on restoring the normal menses cycle flow. The present study provides a new insight and need for clinicians to incorporate the psycho-emotional evaluation into routine care for adolescents with HMB.

Interestingly, adolescents with HMB in this study demonstrated lower mean physical health summary score compared with previous study using the similar PedsQL questionnaire. ${ }^{16}$ The body habitus, region and ethnicity of the studied population could be the contributing factors for this difference. Adolescents with HMB often felt tired, easily fatigue and had difficulty in performing sports activities. Wang et al demonstrated that $79.2 \%$ of adolescents reported that HMB severely affected their ability to participate in sports or physical activities. ${ }^{30}$ This inadvertently resulted to more sedentary life-style and

Table 5 Paediatric Quality of Life-Teen Report Ages 13-18 scores among adolescents with menstrual problems

\begin{tabular}{lllll}
\hline & HMB $(\mathbf{n}=\mathbf{2 0 5})$ & Dysmenorrhoea $(\mathbf{n}=\mathbf{2 2 5})$ & $\begin{array}{l}\text { Amenorrhoea/ } \\
\text { oligomenorrhoea (n=36) }\end{array}$ & $\mathbf{P}$ value \\
\hline PH & $72.27 \pm 18.93$ & $75.17 \pm 15.70$ & $76.39 \pm 16.76$ & 0.328 \\
PS & $67.96 \pm 15.18$ & $69.79 \pm 15.07$ & $68.80 \pm 17.38$ & 0.621 \\
Emotional & $56.08 \pm 21.42$ & $60.09 \pm 20.24$ & $57.92 \pm 21.33$ & 0.226 \\
Social & $76.48 \pm 17.93$ & $79.31 \pm 17.82$ & $75.83 \pm 18.69$ & 0.441 \\
School & $71.32 \pm 18.10$ & $69.98 \pm 16.46$ & $72.64 \pm 18.95$ & 0.665 \\
\hline Total score & $69.46 \pm 14.54$ & $71.35 \pm 12.65$ & $71.44 \pm 15.51$ & 0.534 \\
\hline
\end{tabular}

Analysis of variance test.

All data are presented in mean \pm SD.

$\mathrm{PH}$, physical health summary score; PS, psychosocial health summary score. 
Table 6 Predictors for health-related quality of life

\begin{tabular}{|c|c|c|c|c|}
\hline & \multirow{2}{*}{$\begin{array}{l}\text { Unstandardised } \\
\text { coefficients } \\
\beta\end{array}$} & \multicolumn{2}{|c|}{$95 \% \mathrm{Cl}$ for $\beta$} & \multirow[b]{2}{*}{$P$ value } \\
\hline & & Lower bound & Upper bound & \\
\hline Age & -0.091 & -0.706 & 0.523 & 0.771 \\
\hline BMI & -0.126 & -0.433 & 0.182 & 0.423 \\
\hline Race & 1.113 & -0.634 & 2.861 & 0.211 \\
\hline Job & 1.673 & -0.627 & 3.972 & 0.154 \\
\hline Cigarette & -4.652 & -7.610 & -1.693 & 0.002 \\
\hline Alcohol & -2.870 & -4.673 & -1.067 & 0.002 \\
\hline Sexual & 7.402 & 0.133 & 14.672 & 0.052 \\
\hline Contraception & 11.040 & -2.433 & 24.512 & 0.108 \\
\hline $\begin{array}{l}\text { Taken oral contraception pills for menstrual } \\
\text { problems }\end{array}$ & 7.976 & 2.691 & 13.260 & 0.003 \\
\hline Medical problem & -2.712 & -4.551 & -0.874 & 0.004 \\
\hline
\end{tabular}

Simple logistic regression.

Dependent variable: total score.

$\mathrm{BMI}$, body mass index.

increase obesity among adolescents, leading to a vicious cycle of worsening HMB.

The prevalence of dysmenorrhoea was $30.9 \%$, which constituted moderate, severe and very severe abdominal cramps in this study population. Worldwide, the prevalence ranged from $50 \%$ to $80 \%$ and more than $15 \%$ reported severity which disrupt their daily activities. ${ }^{11} 31$ In studies carried out in Australia, the prevalence was reported to be as high as $94 \%$ in school populations. ${ }^{522}$ Dysmenorrhoea occurred commonly in midadolescents and late adolescents with established ovulatory cycles. ${ }^{27} 32$ In this study, adolescents with dysmenorrhoea were found to be more obese. This was in contrast to other published trials that showed dysmenorrhoea to be inversely related to BMI. ${ }^{33-35}$ However, other studies revealed that dysmenorrhoea occurred more frequently among obese adolescents. ${ }^{3637}$ Obese adolescents are associated with increased adipose tissue and circulating oestrogen, which resulted in oestrogen dominance diseases, and increased prostaglandins which caused dysmenorrhoea.

Studies had showed that dysmenorrhoea resulted in poor academic performance and social activities and directly caused the low school functioning scores. ${ }^{9} 31$ Similarly, the present study demonstrated that adolescents with dysmenorrhoea had the lowest mean score in school function as compare to other menstrual problems. A systemic review showed that nearly $25 \%$ of adolescents were absent from school and majority reported that their academic performance was severely affected by dysmenorrhoea. ${ }^{8}$ In order to overcome the disadvantage of dysmenorrhoea, there was an increased usage of nonsteroidal anti-inflammatory drugs among adolescents with menstrual problems.

Oligomenorrhoea was associated with polycystic ovarian syndrome (PCOS) and these individuals were reported to have high levels of anxiety and depression..$^{10}$ As the result, adolescents with oligomenorrhoea had lower psychosocial scores compared with menorrhagia and dysmenorrhoea group. It was noted that adolescents with PCOS were 3.4 times more likely to be concerned about their future fertility, leading to lower scores in all domains except physical functioning. ${ }^{15}$ Hence, early intervention and treatment should be provided to them as early as possible to improve their psychosocial scores.

This study illustrated the impact of menstrual problems on education among adolescents was significant. The disadvantages among those with menstrual problems were well demonstrated. School abstinence, disability to concentrate on studies, unable to participate in sports or school's physical activities may have long-term consequences for adolescent girls with menstrual problems. These negative effects will start at school and continue unchanged throughout their life. Hence, it is important that their menstrual problems should be addressed properly from the beginning. Teachers should have knowledge about menstrual problem in order for them to be able to educate and provided better emotional support to adolescents. Besides that, teachers should have confidence in providing counselling regarding menstrual topics and refer adolescents who required further care to healthcare providers. ${ }^{38}$ This will ensure those required further attention will receive optimal care as early as possible.

Cigarette smoking, alcohol consumption and concurrent medical illness were all associated with lower quality of life among the study population. Adolescents on oral contraceptive pills for menstrual problems were found to have higher score of HRQL. Previous studies also reported the similar findings. ${ }^{39}$ Hence, contraceptive pills are one of the most effective treatments in HMB 
among young girls with menstrual problems to improve their quality of life.

\section{Limitation}

This study had several limitations. This study was conducted in secondary schools from the Klang Valley, where most of the students were residents of Selangor and Kuala Lumpur. Therefore, our findings may not be applicable to whole adolescents' population in Malaysia. More extensive studies involving multiple schools throughout Malaysia are required to test the outcome of the current study. This was also a cross-sectional descriptive study; therefore, was only able to show the association of variables with functional scores, without allowing true causal relationships to be ascertained. Longitudinal studies would be more appropriate to probe into the cause and effect of each menstrual problem. Furthermore, there were no data regarding the norm for the Malaysian population to compare with the individuals with menstrual problems. This study highlights the need for normogram for the Malaysian population.

\section{CONCLUSION}

Menstrual problems among adolescents have a significant impact on their quality of life. Each menstrual problem affects each domain differently. This calls for a more comprehensive approach towards managing adolescents with menstrual problems. It is possibly wise to screen students at the school level, to identify those individuals with low functional scores and to refer them for proper management at a tertiary adolescent gynaecology centre.

Contributors UM, AAZ and ZAM were involved in the proposal draft, data collection and analysis. KTC and NAAG were involved in original draft preparation. SG involved in finalising the manuscript. The preliminary data in this manuscript had been presented at the RCOG Conference 2012 in Kuching, Sarawak, Malaysia. The authors declare no conflict of interest. All authors are responsible for the content and writing of this paper. NAAG is responsible for the overall content as guarantor.

Funding The authors have not declared a specific grant for this research from any funding agency in the public, commercial or not-for-profit sectors.

\section{Competing interests None declared.}

Patient and public involvement Patients and/or the public were not involved in the design, or conduct, or reporting, or dissemination plans of this research.

\section{Patient consent for publication Not applicable.}

Ethics approval This study involves human participants and was approved by Universiti Kebangsaan Malaysia Research Ethics Committee code of approval: FF-093-2012 and State Health District Office in Selangor and Kuala Lumpur, Malaysia. The study was conducted according to the guidelines of the Declaration of Helsinki. Participants gave informed consent to participate in the study before taking part.

Provenance and peer review Not commissioned; externally peer reviewed. Data availability statement № data are available.

Open access This is an open access article distributed in accordance with the Creative Commons Attribution Non Commercial (CC BY-NC 4.0) license, which permits others to distribute, remix, adapt, build upon this work non-commercially, and license their derivative works on different terms, provided the original work is properly cited, appropriate credit is given, any changes made indicated, and the use is non-commercial. See: http://creativecommons.org/licenses/by-nc/4.0/.

\section{ORCID iDs}

Kah Teik Chew http://orcid.org/0000-0002-6542-386X

Zaleha Abdullah Mahdy http://orcid.org/0000-0003-0856-0697
REFERENCES

1 Mitan LA, Slap GB. Adolescent menstrual disorders. update. Med Clin North Am 2000;84:851-68.

2 Fraser IS, Mansour D, Breymann C, et al. Prevalence of heavy menstrual bleeding and experiences of affected women in a European patient survey. Int J Gynaecol Obstet 2015;128:196-200.

3 El-Hemaidi I, Gharaibeh A, Shehata H. Menorrhagia and bleeding disorders. Curr Opin Obstet Gynecol 2007;19:513-20.

4 Wilson CA, Keye WR. A survey of adolescent dysmenorrhea and premenstrual symptom frequency. A model program for prevention, detection, and treatment. J Adolesc Health Care 1989;10:317-22.

5 Hillen TI, Grbavac SL, Johnston PJ, et al. Primary dysmenorrhea in young Western Australian women: prevalence, impact, and knowledge of treatment. J Adolesc Health 1999;25:40-5.

6 Akinnubi CF. Influence of dysmenorrhea and menorrhagia on academic performance among female students in tertiary institutions in Ondo state Nigeria. WJSS 2016;3:34.

7 Lee LK, Chen PCY, Lee KK, et al. Menstruation among adolescent girls in Malaysia: a cross-sectional school survey. Singapore Med J 2006;47:869.

8 Armour M, Parry K, Manohar N, et al. The prevalence and academic impact of dysmenorrhea in 21,573 young women: a systematic review and meta-analysis. J Womens Health 2019;28:1161-71.

9 Sharma A, Taneja DK, Sharma P, et al. Problems related to menstruation and their effect on daily routine of students of a medical college in Delhi, India. Asia Pac J Public Health 2008;20:234-41.

10 Laggari V, Diareme S, Christogiorgos S, et al. Anxiety and depression in adolescents with polycystic ovary syndrome and MayerRokitansky-Küster-Hauser syndrome. J Psychosom Obstet Gynaecol 2009;30:83-8.

11 Agarwal A, Venkat A. Questionnaire study on menstrual disorders in adolescent girls in Singapore. J Pediatr Adolesc Gynecol 2009;22:365-71.

12 Houston AM, Abraham A, Huang Z, et al. Knowledge, attitudes, and consequences of menstrual health in urban adolescent females. $J$ Pediatr Adolesc Gynecol 2006;19:271-5.

13 Testa MA, Simonson DC. Assessment of quality-of-life outcomes. $N$ Engl J Med Overseas Ed 1996;334:835-40.

14 Chumlea WC, Schubert CM, Roche AF, et al. Age at menarche and racial comparisons in US girls. Pediatrics 2003;111:110-3.

15 Trent ME, Rich M, Austin SB, et al. Quality of life in adolescent girls with polycystic ovary syndrome. Arch Pediatr Adolesc Med 2002;156:556-60.

16 Nur Azurah AG, Sanci L, Moore E, et al. The quality of life of adolescents with menstrual problems. J Pediatr Adolesc Gynecol 2013;26:102-8.

17 Fernández-Martínez E, Onieva-Zafra MD, Parra-Fernández ML. The impact of dysmenorrhea on quality of life among Spanish female university students. Int J Environ Res Public Health 2019;16:713.

18 Ruta DA, Garratt AM, Russell IT. Patient centred assessment of quality of life for patients with four common conditions. Qual Health Care 1999;8:22-9.

19 Varni JW, Seid M, Rode CA. The PedsQL: measurement model for the pediatric quality of life inventory. Med Care 1999;37:126-39.

20 Varni JW, Seid M, Kurtin PS. PedsQL 4.0: reliability and validity of the pediatric quality of life inventory version 4.0 generic core scales in healthy and patient populations. Med Care 2001;39:800-12.

21 Ozerdogan N, Sayiner D, Ayranci U, et al. Prevalence and predictors of dysmenorrhea among students at a university in turkey. Int $J$ Gynaecol Obstet 2009;107:39-43.

22 Parker MA, Sneddon AE, Arbon P. The menstrual disorder of teenagers (MDOT) study: determining typical menstrual patterns and menstrual disturbance in a large population-based study of Australian teenagers. BJOG 2010;117:185-92.

23 Alagappan M, Rampal L, Zalilah MS. Prevalence of overweight/ obesity and its associated factors among secondary school students in semi urban area in Malaysia. Med J Malaysia 2019;74:513-20.

24 Ahmad A, Zulaily N, Shahril MR, et al. Association between socioeconomic status and obesity among 12-year-old Malaysian adolescents. PLoS One 2018;13:e0200577.

$25 \mathrm{Hj}$ Ramli NH, Alavi M, Mehrinezhad SA, et al. Academic stress and self-regulation among university students in Malaysia: mediator role of mindfulness. Behav Sci 2018;8:12.

26 Mansor AA, Abdullah H, Azman A. Sedentary lifestyle and body weight status among youth at public secondary schools in Selangor. IJARBSS 2017;7:652-8.

27 Adams Hillard PJ, Adams PH. Adolescent menstrual health. Pediatr Endocrinol Rev 2006;3 Suppl 1:138-45.

28 Torres R, Zajer C, Menendez M, et al. Heavy menstrual bleeding affects quality of life in adolescents, 2017. 
29 Pawar A, Krishnan R, Davis K, et al. Perceptions about quality of life in a school-based population of adolescents with menorrhagia: implications for adolescents with bleeding disorders. Haemophilia 2008:14:579-83.

30 Wang W, Bourgeois T, Klima J, et al. Iron deficiency and fatigue in adolescent females with heavy menstrual bleeding. Haemophilia 2013;19:225-30.

31 Singh A, Kiran D, Singh $\mathrm{H}$, et al. Prevalence and severity of dysmenorrhea: a problem related to menstruation, among first and second year female medical students. Indian J Physiol Pharmacol 2008;52:389-97.

32 Polat A, Celik H, Gurates B, et al. Prevalence of primary dysmenorrhea in young adult female university students. Arch Gynecol Obstet 2009;279:527-32.

33 Parazzini F, Chiaffarino F, Surace M, et al. Selected food intake and risk of endometriosis. Hum Reprod 2004;19:1755-9.

34 Chauhan M, Kala J. Relation between dysmenorrhea and body mass index in adolescents with rural versus urban variation. $J$ Obstet Gynaecol India 2012;62:442-5.
35 Signorello LB, Harlow BL, Cramer DW, et al. Epidemiologic determinants of endometriosis: a hospital-based case-control study. Ann Epidemiol 1997;7:267-74.

36 Tembhurne S, Mitra M. Relationship between body mass composition and primary dysmenorrhoea. Ind Jour of Physioth and Occupat Therapy - An Inter Jour 2016;10:76-81.

37 Mohapatra D, Mishra T, Behera M, et al. A study of relation between body mass index and dysmenorrhea and its impact on daily activities of medical students. Asian J Pharm Clin Res 2016;9:297-9.

38 Duffy B, Fotinatos N, Smith A, et al. Puberty, health and sexual education in Australian regional primary schools: year 5 and 6 teacher perceptions. Sex Educ 2013;13:186-203.

39 Kristjánsdóttir J, Sundelin C, Naessen T. Health-Related quality of life in young women starting hormonal contraception: a pilot study. Eur J Contracept Reprod Health Care 2018;23:171-8.

40 Williams SL, Parisi SM, Hess R, et al. Associations between recent contraceptive use and quality of life among women. Contraception 2012;85:282-7. 